\title{
Internalization of cell-derived microparticles triggers endothelial pro-inflammatory responses
}

\author{
Phatchanat Klaihmon, ${ }^{1}$ Archrob Khuhapinant, ${ }^{2}$ Wasinee Kheansaard, ${ }^{3}$ Kovit Pattanapanyasat ${ }^{4}$
}

\begin{abstract}
Background: Increased numbers of circulating microparticles (MPs) have long been documented in thalassemia and are considered as a contributing factor in developing the thromboembolic events (TEEs), which are associated with endothelial dysfunction. Indeed, the cellular and molecular mechanisms by which MPs and endothelial cells interact and their consequences remain poorly investigated.
\end{abstract}

Objective: The present study aims to compare the biological effects of MPs obtained from healthy subjects and $\beta$-thalassemia/HbE patients on endothelial pro-inflammatory responses.

Methods: MPs isolated from plasma by two-step centrifugation from 10 healthy donors, 19 splenectomized and 30 non-splenectomized $\beta$-thalassemia/HbE patients were first characterized for their cellular origins, then counted and incubated with primary human umbilical vein endothelial cells (HUVECs). Internalization of MPs into HUVECs and their induction on endothelial cell activation and pro-inflammatory responses were determined.

Results: MPs either from healthy or $\beta$-thalassemia/HbE patients could become internalized into endothelial cells, but unlike MPs from healthy donors and non-splenectomized patients, MPs from splenectomized patients were the most active and induced the 2-fold up-regulation of pro-inflammatory genes, IL1B, CXCL8, and CCL 2 and 4 -fold increase in interleukin-1 $\beta$. In addition, MPs from both healthy subjects and splenectomized patients at $10^{6} / \mathrm{ml}$ failed to trigger the secretion of endothelial IL- 6 and IL- 8 while higher MP concentration at $5 \times 10^{6} / \mathrm{ml}$ significantly induced this secretion.

Conclusion: Plasma MPs isolated from splenectomized $\beta$-thalassemia/HbE patients are capable of triggering pro-inflammatory responses from endothelial cells reflected at both gene and protein levels.

Key words: endothelial cells, hypercoagulation, microparticles, thalassemia, pro-inflammatory cytokines

\section{From:}

${ }^{1}$ Siriraj Center of Excellence for Stem Cell Research, Faculty of Medicine Siriraj Hospital, Mahidol University, Bangkok, Thailand

Division of Hematology, Department of Medicine,

Faculty of Medicine Siriraj Hospital, Mahidol University, Bangkok, Thailand

Department of Clinical Microscopy, Faculty of Medical Technology, Mahidol University, Nakhon Pathom, Thailand

${ }^{4}$ Siriraj Center of Research Excellence in Microparticle and Exosome in Diseases, Department of Research and Development, Faculty of Medicine Siriraj Hospital, Mahidol University, Bangkok, Thailand

Corresponding author:

Kovit Pattanapanyasat

Department of Research and Development,

Faculty of Medicine Siriraj Hospital, Mahidol University,

Bangkok 10700, Thailand

E-mail: kovit.pat@mahidol.ac.th

\section{Introduction}

Patients with $\beta$-thalassemia/ $\mathrm{HbE}$ disease are at increased risk of thromboembolic events (TEEs) because of a hypercoagulable state, and this risk is likely to be highest in patients with non-transfusion-dependent thalassemia or who have undergone splenectomy. ${ }^{1-3}$ TEEs are one of the major clinical complications of thalassemia, resulting in notable morbidity and mortality. ${ }^{4}$ The underlying molecular and cellular mechanisms associated with the hypercoagulable state are multiple, such as abnormal erythrocytes, chronic platelet activation and aggregation, hemostatic disturbance, and endothelial cell dysfunction. ${ }^{5}$

Lining endothelial cells serve as key modulators in the control of vascular homeostasis. The physiologic status of vascular endothelial cells in patients with thalassemia is disturbed, as demonstrated by elevated levels of soluble adhesion molecules such as ICAM-1, E-selectin, VCAM-1, von Willebrand factor, and tumor necrosis factor- $\alpha$ (TNF- $\alpha) \cdot{ }^{6-7}$ 
This prompts endothelial cells to be in a prothrombotic state. In addition, other cell sources of microparticles (MPs) (such as platelets, leukocytes and erythrocytes) significantly increase endothelial cell-derived MPs in thalassemia patients. ${ }^{8,9}$ These factors contribute to, and aggravate, hypercoagulability.

Our group has demonstrated significantly increased levels of circulating MPs in thalassemia patients who have undergone splenectomy in comparison to both non-splenectomized patients and healthy individuals, and that the majority of these MPs are shed from platelets and erythrocytes. ${ }^{10,11}$ Proteomic analysis of thalassemia MPs revealed that they contained high levels of reactive oxygen species, heat shock protein and other chaperones, that could facilitate the TEE process observed in thalassemia patients. ${ }^{12} \mathrm{We}$ also found that there were procoagulant effects of thalassemia MPs on platelet activation and leukocyte-platelet aggregation. ${ }^{13}$ Recently, Kheansaard et al. substantiated that MPs from splenectomized patients induce endothelial cell activation and subsequent endothelial-monocyte adhesion by enhancing the expression of pro-coagulant mediator, inflammatory cytokines as well as endothelial adhesion molecules. ${ }^{14}$ However, other endothelial pro-inflammatory markers up-regulated by exposure to MPs have not yet been documented. We reasoned that a more detailed study on certain pro-inflammatory genes including IL1B, IL6, CXCL8, CD40 and CCL2 along with their cytokines may provide some important clues as to the potential roles of MPs from $\beta$-thalassemia/HbE patients on endothelial cells. Hence the rationale for the studies reported herein.

\section{Methods}

\section{Subjects and blood sample collection}

This study was carried out in accordance with the Helsinki Declaration and was approved by the Institutional Review Board, Faculty of Medicine, Siriraj Hospital, Ethical Approved Number 540/2557 (EC2). Peripheral venous blood was drawn from the 10-12 hours fasting 10 healthy subjects, 19 splenectomized patients and 30 non-splenectomized patients. No evidence of concurrent infection, vaso-occlusive episode, or inflammation was found in subjects recruited. None had been hospitalized nor received blood transfusion within 1 month. All blood samples were collected by venipuncture, held at room temperature, and processed within 2-3 hours. Informed consent was obtained from each participant prior to blood collection.

\section{Isolation of peripheral blood MPs}

Peripheral blood MPs were prepared as described in the previous study. ${ }^{14}$ Briefly, $10 \mathrm{ml}$ of fresh whole blood samples collected in $3.2 \%$ trisodium citrate anticoagulant were centrifuged at $1,500 \times \mathrm{g}$ for $15 \mathrm{~min}$ at $25^{\circ} \mathrm{C}$ to collect platelet-poor plasma and then re-centrifuged at $14,000 \times \mathrm{g}$ for $2 \mathrm{~min}$ at $4^{\circ} \mathrm{C}$ to obtain platelet-free plasma (PFP). One hundred microliter of MP pellets were collected after centrifugation of PFP at $14,000 \times \mathrm{g}$ at $4^{\circ} \mathrm{C}$ for another $45 \mathrm{~min}$, washed once with $2 \mathrm{ml}$ of Dulbecco's phosphate-buffered saline (DPBS), and resuspended with $200 \mu \mathrm{l}$ DPBS.

\section{Characterization of origin of MPs}

Total numbers and cellular origins of MPs in peripheral blood samples and pellet MP samples were determined using the flow cytometry technique described in the previous study. ${ }^{10-11}$ Briefly, $5 \mu \mathrm{l}$ MP sample was stained in $95 \mu$ filtered annexin V-binding buffer containing $1 \mu \mathrm{l}$ each of anti-CD235a (erythrocyte marker) conjugated with fluorescein isothiocyanate (FITC), anti-CD146 (endothelial cell marker) conjugated with phycoerythrin/cyanin 7 (PE/Cy7), anti-CD45 (leucocyte marker) conjugated with peridinin chlorophyll protein (Per$\mathrm{CP}$ ), anti-CD41a (platelet marker) conjugated with allophycocyanin (APC), and annexin V (phosphatidylserine marker) conjugated with phycoerythrin (PE). All monoclonal antibodies were purchased from Becton Dickinson Biosciences (BD Biosciences, San Jose, CA). After 15 min of incubation, $400 \mu \mathrm{l}$ annexin $\mathrm{V}$-binding buffer were added and sample was transferred into TruCount ${ }^{\mathrm{TM}}$ beads (BD Biosciences). Data were acquired and analyzed with the use of a FACS Canto II flow cytometer and FACS Diva software (BD Biosciences). MP populations were determined by comparison with beads of $0.2,0.58,0.75$ and $1.3 \mu \mathrm{m}$ in diameter (Spherotech, Inc., Lake Forest, IL). Instrument noise and background were excluded by running the pre-filtered buffer. The absolute number of MPs was calculated using the formulae: [(annexin- $\mathrm{V}^{+}$events $\mathrm{X}$ number of beads in each tube $\mathrm{X}$ dilution factor) / (number of collected beads X total sample volume)].

\section{Endothelial cell culture and MP exposure}

Primary human umbilical vein endothelial cells (HUVECs) were cultivated in endothelial growth medium (EGM-2 medium, Lonza Group Ltd, Basel, Switzerland) at $37^{\circ} \mathrm{C}$ in humidified $5 \% \mathrm{CO}_{2}$ incubator. $5 \times 10^{4}$ HUVECs were plated on fibronectin-coated 12-well plates overnight to reach $80-90 \%$ confluence, and primed or unprimed with $10 \mathrm{ng} / \mathrm{ml}$ TNF- $\alpha$ (Sigma-Aldrich, St. Louis, MO) for 1 hour before addition of MPs. Then, $10^{6}$ MPs (for detection of mRNA and intracellular cytokines), and $10^{6}$ and $5 \times 10^{6} \mathrm{MPs}$ (both concentrations used for detection of secreting cytokines) were added in $1 \mathrm{ml}$ of culture medium for 12 hours; then $5 \mu \mathrm{g} / \mathrm{ml}$ of a protein transporting inhibitor brefeldin A (Biolegend) was added to block cytokine secretion for intracellular cytokine detection. At the end of experiment, supernatants were collected and HUVECs were washed with phosphate buffered saline (Gibco, NY), trypsinized and harvested for determination of pro-inflammatory cytokine production.

Internalization of MPs by HUVECs was also examined by confocal microscopy analysis. MPs were labeled with $2 \mu \mathrm{M}$ PKH26 red fluorescent cell linker kits (Sigma-Aldrich) for 5 min at RT. HUVECs were treated with labeled MPs either isolated from healthy subjects or $\beta$-thalassemia/ $\mathrm{HbE}$ patients at concentration $5 \times 10^{6}$ particles $/ \mathrm{ml}$ for $2 \mathrm{~h}$ at $37^{\circ} \mathrm{C}, 5 \% \mathrm{CO}_{2}$. Then non-adherent MPs were removed by gently washing 3 times with PBS. HUVECs were fixed with $4 \%$ formaldehyde for $30 \mathrm{~min}$ and stained with F-actin staining kit-green fluorescence (Abcam, Cambridge, UK) for $60 \mathrm{~min}$ at RT. Slides were washed and mounted using mounting buffer containing $0.5 \mu \mathrm{g} / \mathrm{ml}$ DAPI (X-ZELL, Sunnyvale, CA). Serial Z-stacked confocal imaging was performed with an A1R confocal 
microscope (Nikon, Tokyo, Japan), and image analysis was performed with NIS Element Viewer 4.2 software (Nikon).

\section{Flow cytometric analysis of intracellular cytokines}

HUVECs were permeabilized and fixed in Permeablization/Fixation solution (BD Biosciences) according to manufacturer's instructions. Cells were intracellularly stained with a combination cocktail purchased from BD Biosciences comprised $2 \mu \mathrm{l}$ each of FITC-anti-IL-1 $\beta$, PE-anti-MCP1, PerCP/ Cy5.5-anti-CD40 and PE-Texas red-anti-IL-8 for $30 \mathrm{~min}$ at $4^{\circ} \mathrm{C}$. Samples were washed and at least 20,000 events were acquired suing a FACS Canto II flow cytometer.

\section{Analysis of secreted cytokine by ELISA}

Due to the limited volume of supernatant, $1 \mathrm{ml}$ of culture supernatants collected from HUVECs co-incubated with MPs from healthy donors and splenectomized thalassemia patients were centrifuged to deplete cells and debris at 14,000 $\mathrm{g}$ for 1 hour at $4^{\circ} \mathrm{C}$ to ensure that the MPs added were pelleted, and then collect $0.9 \mathrm{ml}$ supernatant in $-80^{\circ} \mathrm{C}$ refrigerator until use. IL-6 and IL-8 levels were quantified using ELISA kits (ImmunoTools, Friesoythe, Germany) according to the manufacturer's recommendations.

\section{Quantitative RT-PCR}

One $\mu \mathrm{g}$ of total mRNA extracted from HUVECs by Trizol reagent (Thermo Fisher Scientific, Walthma, MA) was utilized to synthesize cDNA using RevertAid First Strand cDNA Synthesis Kit (Thermo Fisher Scientific). Pro-inflammatory cytokine mRNA was quantitated by qPCR using a SYBR Select master mix (Applied Biosystem, Foster Ciity, CA). Primers used are listed in Table S1. The levels of target gene expression were normalized against GAPDH expression.

\section{Statistical analysis}

Data were expressed as mean \pm SEM. A few outlying values resulted from biological variation that would impact the assay results were excluded before subjecting to statistical analysis. Comparisons between parameters were analyzed with a non-parametric Mann-Whitney U-test. The threshold for statistical significance for all comparisons was $p<0.05$.

\section{Results}

Hematological parameters and blood microparticle profiles

Complete blood counts revealed severe anemia in both splenectomized and non-splenectomized $\beta$-thalassemia/ $\mathrm{HbE}$ patients compared to healthy individuals (Table 1). Apart from hematological abnormalities, plasma MPs from splenectomized thalassemic patients exhibited higher numbers of circulating annexin- $\mathrm{V}^{+}$MPs $(p=0.0372$ vs healthy subjects; $p=$ 0.0347 vs non-splenectomized group, Figure 1A), which were derived from many cell sources including CD41a $\mathrm{a}^{+}$platelets $(p$ $=0.0249$ vs healthy subjects, Figure 1B), CD235a ${ }^{+}$erythrocytes ( $p=0.0219$ vs healthy subjects; $p=0.0047$ vs non-splenectomized group, Figure 1C), CD $45^{+}$leukocytes (Figure 1D) and $\mathrm{CD}_{146^{+}}$endothelial cells (Figure 1E). Increased amounts of circulating MPs could play an important role in the hypercoagulable state of thalassemia patients.

Table 1. Hematologic parameters of subjects recruited in this study.

\begin{tabular}{|c|c|c|c|}
\hline & \multirow[b]{2}{*}{ Normal } & \multicolumn{2}{|c|}{$\beta$-thalassemia/HbE } \\
\hline & & $\begin{array}{l}\text { Non-splenec- } \\
\text { tomized }\end{array}$ & $\begin{array}{l}\text { Splenecto- } \\
\text { mized }\end{array}$ \\
\hline Age (years) & $34.3 \pm 4.2$ & $35.0 \pm 4.3$ & $32.3 \pm 10.2$ \\
\hline $\operatorname{Sex}(M / F)$ & 4/6 (10) & $15 / 15(30)$ & 8/11 (19) \\
\hline WBC count $\left(10^{3} / \mu \mathrm{l}\right)$ & $7.1 \pm 1.9$ & $8.3 \pm 4.5$ & $15.6 \pm 9.9^{* *, * * * *}$ \\
\hline $\mathrm{RBC}$ count $\left(10^{6} / \mu \mathrm{l}\right)$ & $4.9 \pm 0.5$ & $3.4 \pm 0.5^{\star}$ & $3.0 \pm 0.5^{* * *, \# *}$ \\
\hline $\mathrm{Hb}(\mathrm{g} / \mathrm{dL})$ & $14.2 \pm 1.7$ & $6.6 \pm 1.2^{* * *}$ & $6.3 \pm 1.3^{* * *}$ \\
\hline Hct (\%) & $43 \pm 0.5$ & $21 \pm 3.0^{* * *}$ & $21 \pm 3.8^{* * *}$ \\
\hline MCV (fL) & $89 \pm 4.3$ & $63 \pm 8.7^{* * *}$ & $71 \pm 5.8^{* *, \# \#}$ \\
\hline $\mathrm{MCH}(\mathrm{pg})$ & $29 \pm 1.8$ & $19 \pm 2.6^{* * *}$ & $21 \pm 2.2^{* *}$ \\
\hline MCHC (\%) & $33 \pm 0.7$ & $31 \pm 2.0$ & $29 \pm 2.3^{* *, \# \#}$ \\
\hline NRBC (/100 WBC) & 0 & $98 \pm 185.4$ & $438 \pm 512.6^{\# \# \#}$ \\
\hline PLT count $\left(10^{3} / \mu \mathrm{l}\right)$ & $249 \pm 29.8$ & $260 \pm 153.5^{*}$ & $700 \pm 243.7^{\# \# \#}$ \\
\hline
\end{tabular}

Note: ${ }^{*}{ }^{* *},{ }^{* * *}$ compared to normal individuals;

$\#$,\#\# compared to non-splenectomized $\mathrm{HbE} / \beta$-thalassemia group
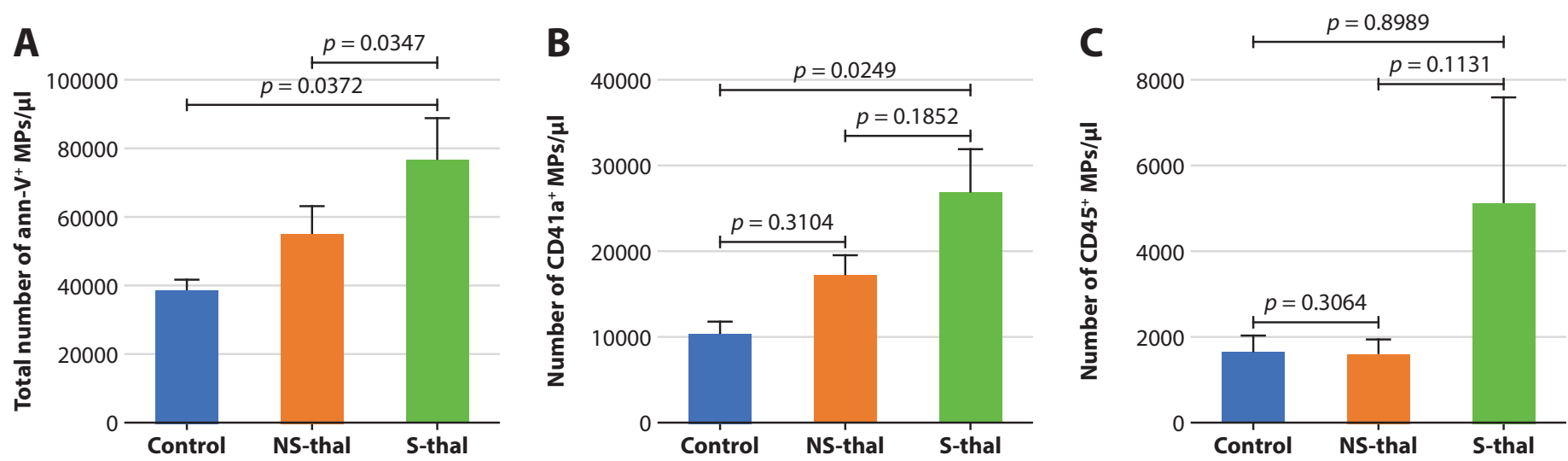

Figure 1. Profiles of circulating MPs in healthy subjects and thalassemia patients.

The absolute numbers of total annexin- $\mathrm{V}^{+}$MPs (A), CD41a ${ }^{+}$platelet MPs (B), CD235a $\mathrm{a}^{+}$erythrocyte MPs (C), CD45 ${ }^{+}$leukocyte MPs (D) and CD146 ${ }^{+}$endothelial cell MPs (E) in healthy subjects, non-splenectomized and splenectomized $\beta$-thalassemia/HbE patients. 

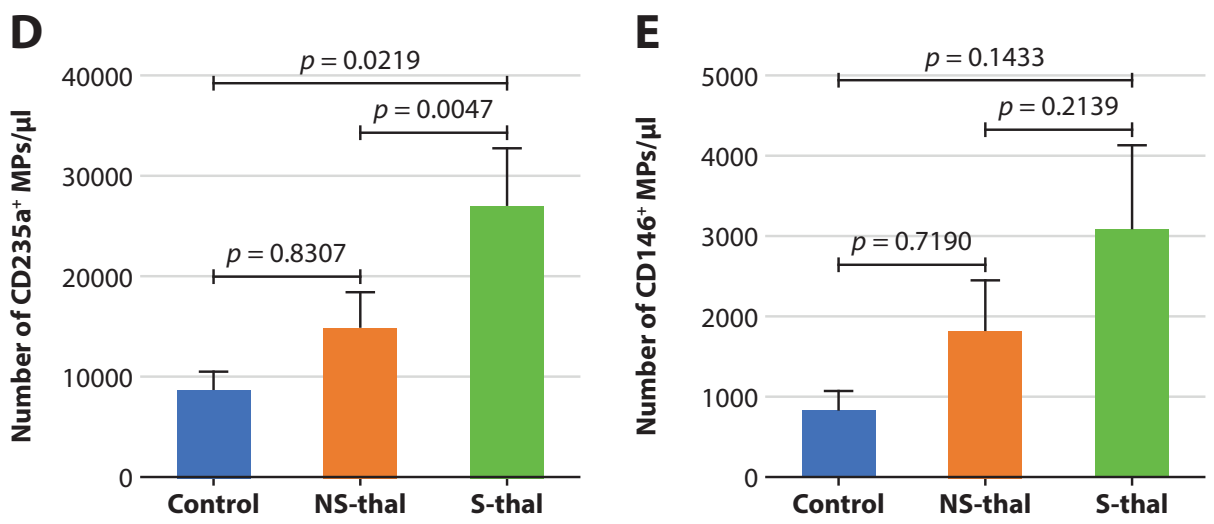

Figure 1. (Continued)
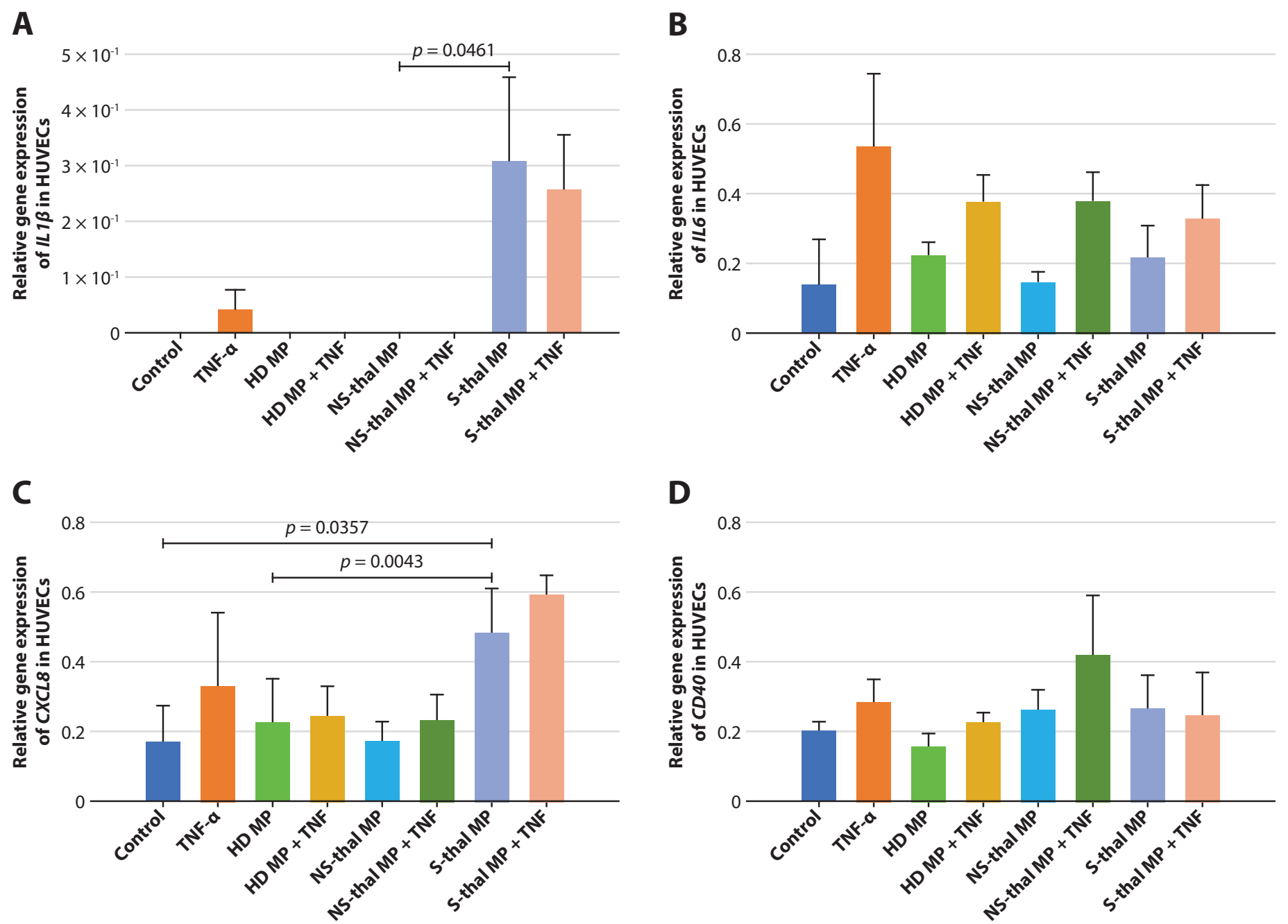

Figure 2. Real-time PCR analyses of pro-inflammatory cytokine-related genes in HUVECs. mRNA levels of pro-inflammatory genes, including $I L 1 \beta(\mathbf{A}), \operatorname{IL6}(\mathbf{B}), C X C L 8(\mathbf{C}), C D 40$ (D), and CCL2 (E) in HUVECs treated with $10^{6} \mathrm{MPs} / \mathrm{ml}$ isolated from healthy subjects, non-splenectomized and splenectomized $\beta$-thalassemia/HbE patients for 12 hours. TNF- $\alpha$ was used as a positive control and as a synergistic agent together with MPs. 


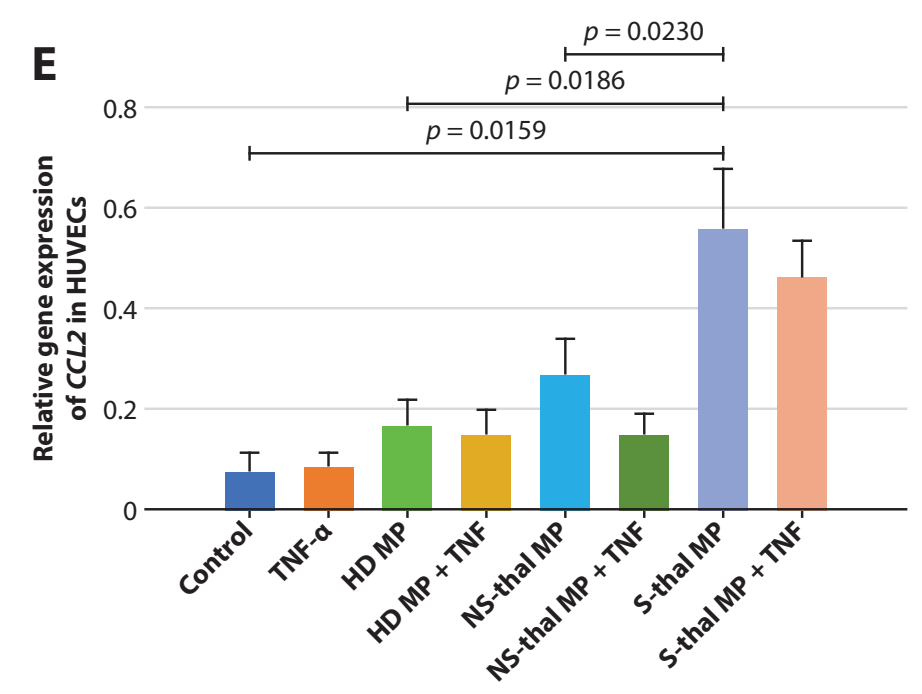

Figure 2. (Continued)

Induction of pro-inflammatory genes in MP-treated HUVECs

Co-culture of HUVECs and MPs results in internalization of MPs and subsequent activation of endothelial cells. The stacking images of confocal microscope revealed that MPs isolated either from healthy subjects or from $\beta$-thalassemia/HbE patients were internalized into the HUVEC recipient cells at 2 $\mathrm{h}$ (Figure S1). We next investigated whether engulfed MPs induced up-regulation of pro-inflammatory cytokine genes. Real-time PCR analysis showed significant increases in mRNA transcript levels of pro-inflammatory cytokines, including $I L 1 B, C X C L 8$, and CCL2, which encode interleukin-1 $\beta$ (IL-1 $\beta$ ) ( $p=0.0461$ vs non-splenectomized group), IL-8 ( $p=0.0043$ vs healthy subjects), and monocyte chemoattractant protein 1 (MCP-1) ( $p=0.0186$ vs healthy subjects; $p=0.0230$ vs non-splenectomized group) in HUVECs, after treatment with $10^{6} \mathrm{MPs}$ isolated from splenectomized $\beta$-thalassemia/HbE patients for 12 hours in comparison to HUVECs exposure with MPs from healthy individuals and non-splenectomized group (Figures 2A-2E). MPs isolated from healthy individuals and

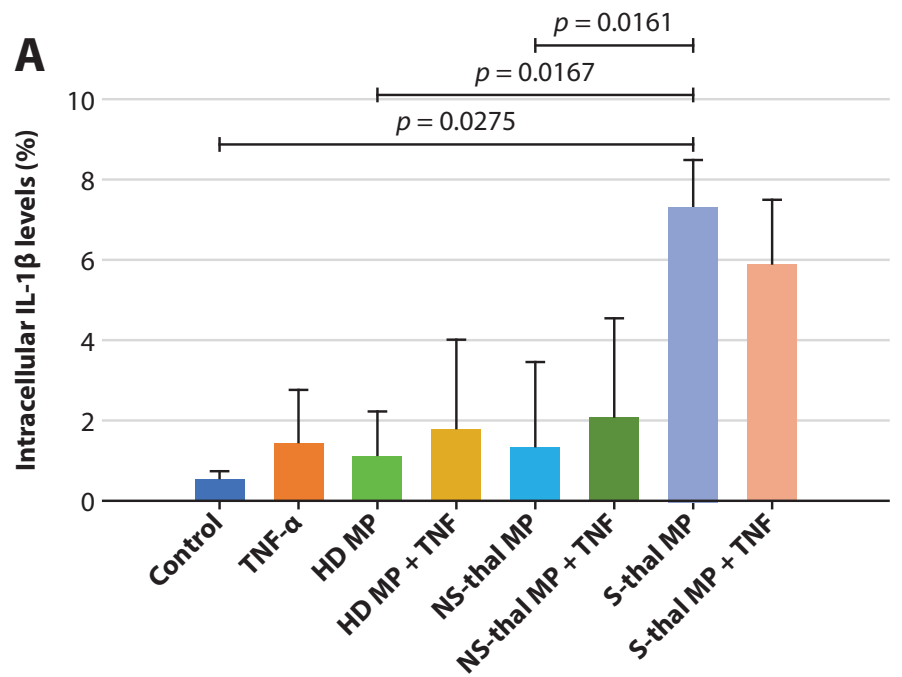

non-splenectomized thalassemia patients did not trigger the up-regulation of these genes more than untreated HUVECs.

\section{Production of intracellular pro-inflammatory cytokines in MP-treated HUVECs}

As the genes encoding pro-inflammatory cytokines in endothelial cells were up-regulated by MP treatment, we also ascertained their product levels by intracellular cytokine staining and measurement. We found that splenectomized thalassemia patients-derived MPs significantly induced intracellular production of endothelial IL-1 $\beta$ compared to other MP sources ( $p=0.0167$ vs healthy subjects; $p=0.0161$ vs non-splenectomized group, Figures $3 \mathrm{~A}$ ), while IL-6 production were not significantly different among group (Figure $3 B$ ). Other pro-inflammatory mediators IL-8, CD40, and MCP-1 were not significantly different in HUVECs treated with MPs isolated from healthy donors, splenectomized and non-splenectomized patients (Figures 3C-3E).

B

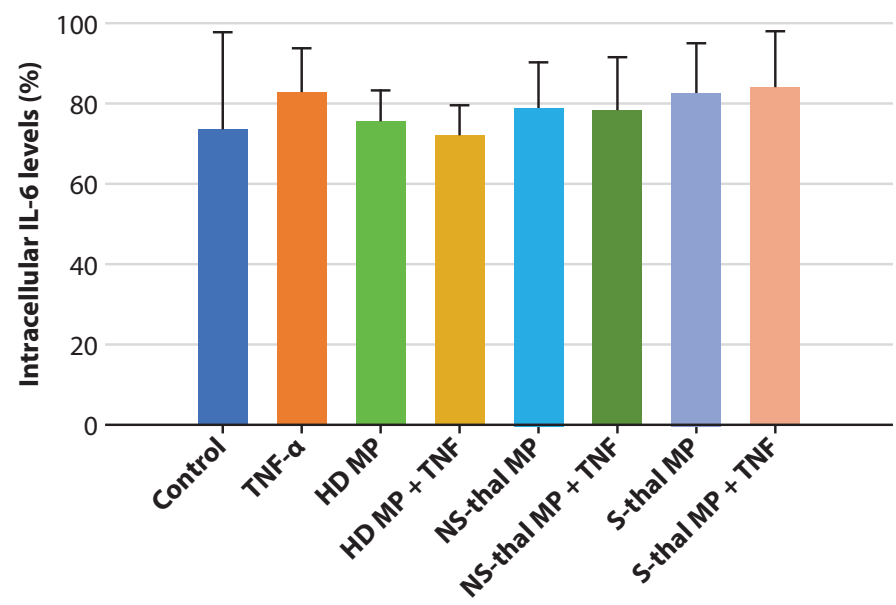

Figure 3. Flow cytometric analysis of pro-inflammatory cytokine produced by HUVECs. Intracellular and surface staining of pro-inflammatory cytokines and chemokines, including IL1 $\beta$ (A), IL6 (B), CXCL8 (C), CD40 (D), and CCL2 (E) in HUVECs treated with $10^{6} \mathrm{MPs} / \mathrm{ml}$ isolated from healthy subjects, non-splenectomized and splenectomized $\beta$-thalassemia/HbE patients for 12 hours. TNF- $a$ was used as a positive control and as a synergistic agent together with MPs. 
APJAI

C

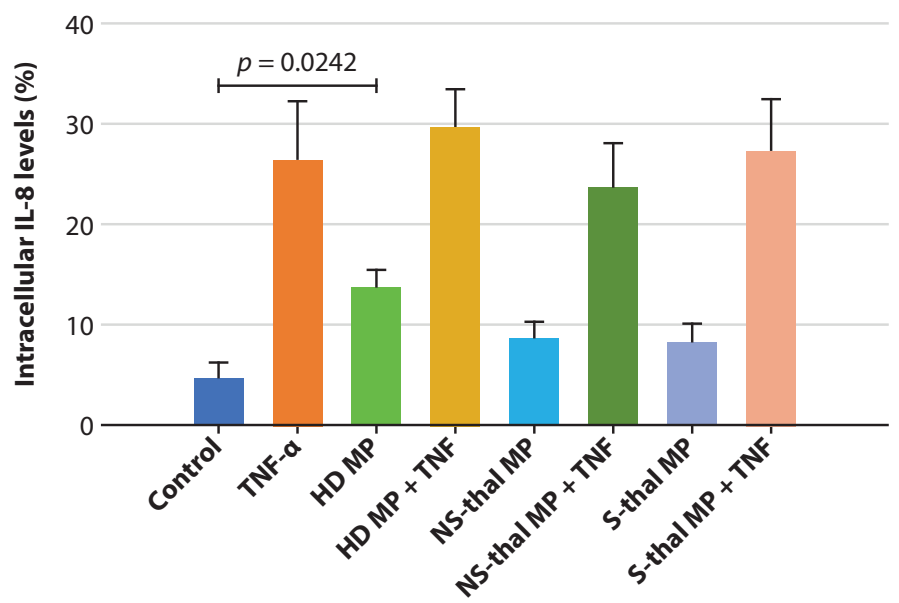

D

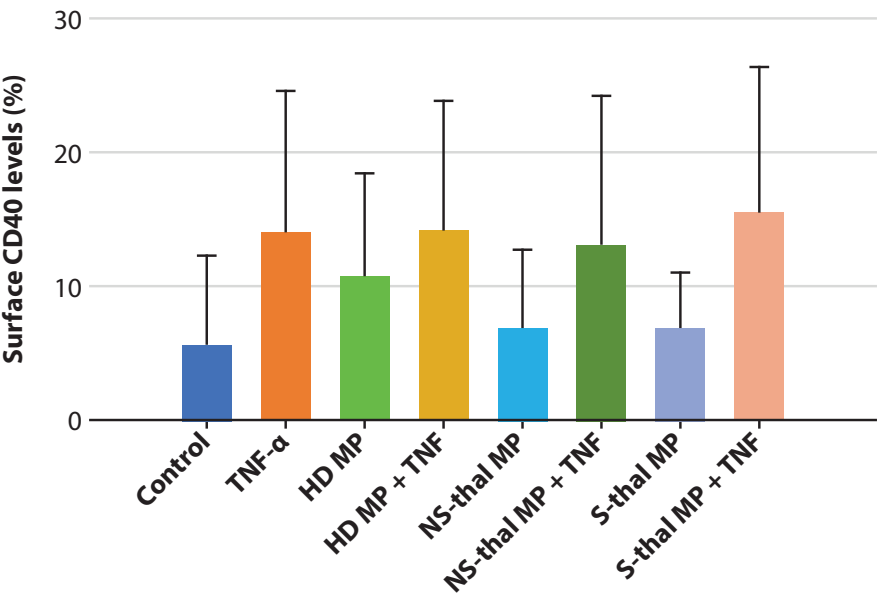

Figure 3. (Continued)

\section{$\mathbf{E}$}
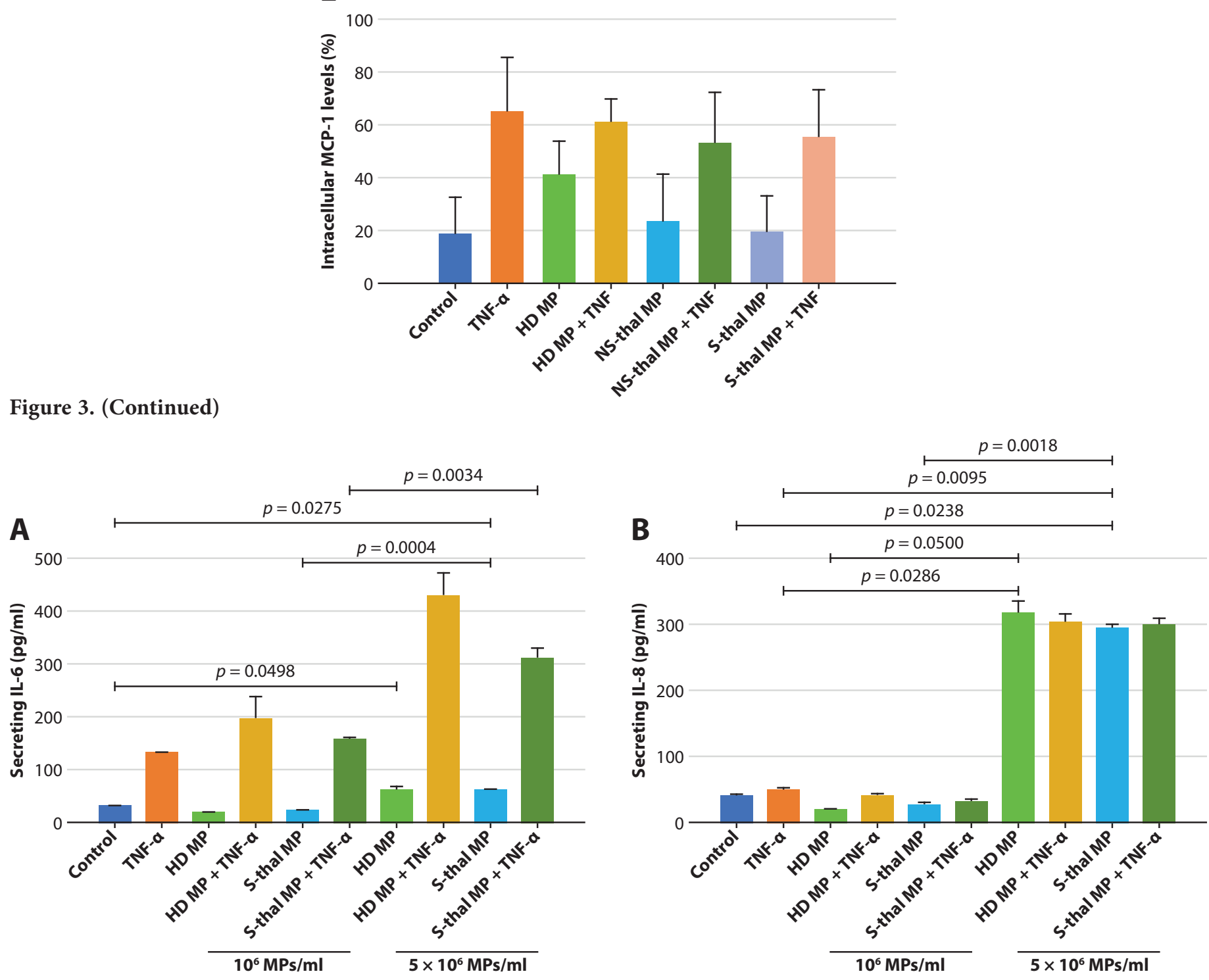

Figure 4. Quantitative measurements of candidate pro-inflammatory cytokines released by HUVECs. ELISA analysis of pro-inflammatory cytokines, including IL-6 (A) and IL-8 (B) secreted from HUVECs treated with $1 \times 10^{6}$ or $5 \times 10^{6} \mathrm{MPs} / \mathrm{ml}$ isolated from healthy subjects and splenectomized $\beta$-thalassemia/HbE patients for 12 hours. TNF- $\alpha$ was used as a positive control and as a synergistic agent together with MPs. 


\section{Secretion of pro-inflammatory cytokines from MP-stimulated HUVECS}

To determine whether MPs isolated from splenectomized thalassemia patients were capable of inducing endothelial cell inflammation superior to MPs from healthy subjects, we further measured by ELISA for the secretion of IL- 6 and IL- 8 in culture medium after exposure of HUVECs to either healthy or splenectomized thalassemia MPs. A high dose of MPs $(5 \times$ $10^{6}$ particles $/ \mathrm{ml}$ ) from splenectomized patients, but not from healthy donors, significantly provoked the secretion of both IL-6 ( $p=0.0004$, Figure 4A). For IL-8, MPs at high dose either from splenectomized patients or healthy donors, significantly induced IL- 8 production ( $p=0.0018, p=0.050$, Figure 4B) from HUVECs in comparison to a low dose of MPs $\left(10^{6}\right.$ particles/ml) treatment. In fact, TNF- $\alpha$ enhanced only IL-6 (and not IL-8) production and secretion.

\section{Discussion}

Even though biogenesis and release of MPs are physiological processes, increased amounts of circulating MPs are involved in several human diseases. The role of MPs in blood disorders is interesting and promising with regard to important advances in diagnostics and therapeutics. Increased MP amounts in thalassemia patients with thromboembolism are considered a useful biomarker ${ }^{15}$ and may have a pathological role in developing clinical complications. Given the functional attributes of MPs, there is evidence supporting their role in promoting phenotypic change of target cells that internalize MPs. For instance, we have demonstrated previously that MPs prepared from splenectomized $\beta$-thalassemia patients are more capable of bridging and stabilizing platelet-leukocyte microaggregates in vitro. ${ }^{13}$ This finding supports Kaewvichit's work in which they found hyperaggregation of platelet-leukocyte complexes, particularly neutrophil and monocyte populations, in splenectomized $\beta$-thalassemia/HbE patients. ${ }^{16}$

In addition to interacting with peripheral leukocytes, MPs also communicate with endothelial cells in initiating the formation of thrombus via the leukocyte-MP-endothelial cell complex. Circulating erythrocyte MPs in sickle cell disease carry and transfer laden heme into endothelial cells, triggering endothelial cell oxidative stress and apoptosis. ${ }^{17}$ Treatment of neutrophil-derived MPs induces a myeloperoxidase-dependent loss of HUVEC membrane integrity and morphological alterations. ${ }^{18}$ These observations led us to hypothesize that excessive circulating MPs in $\beta$-thalassemia patients, especially who undergone splenectomy, could interact with endothelial cells and provoke functional phenotypic change and so contribute to the pathogenesis of the hypercoagulable state. Splenectomy could modify MP properties, for instance, inducing higher circulating MPs, affecting MP cargo as well as changing ratio of MPs regarding their originating cell source. Splenectomized mice have a tendency toward persistent thrombus formation, an increase of platelet-leukocyte aggregates and higher numbers of platelet MPs. ${ }^{19}$ Platelet MPs, but not erythrocytes MPs, are reported to be increased and more pro-coagulant in $\beta$-thalassemia patients who have received intensive blood transfusion and undergone splenectomy. ${ }^{11,20}$
The cellular response to stress stimuli is considerably complicated. Exposure with plasma MPs triggered the production of pro-inflammatory mediators, including TNF- $\alpha$, IL-6, IL-8 and MCP-1 secreted from endothelial cells, bronchial epithelial cells, and podocytes in a time- and dose-dependent manner. ${ }^{14,21,22}$ In the present study, we found increased transcript levels of CCL2, CXCL8, and $I L 1 B$ as well as its protein product, IL- $1 \beta$, in HUVECs cultured for short periods of time (12 hours) in the presence of MPs from splenectomized thalassemic patients. IL- 6 and IL- 8 can be produced and secreted by endothelial cells; however, there was no significant difference of these two cytokines in HUVECs treated with different MP source when we detected by using intracellular cytokine staining. We were then obliged to measure these cytokines' secretion in endothelial culture supernatants. In addition, there was no difference of gene expression of pro-inflammatory cytokine in control HUVECs unprimed and primed with TNF- $\alpha$, a slight increase of mRNA levels was found in TNFa primed cells. Biological variation resulted from treatment with MPs isolated from different donors cannot be excluded and could strongly affect the phenotype of target cells. Targeting of TNF receptor in endothelial cells resulted in reduction of pro-inflammatory response and apoptosis of endothelial cells, ${ }^{23}$ and could alleviate the MP-induced endothelial cell inflammation and dysfunction.

Not only biological components packaged inside of MPs, but concentration of MPs also has a great effect on the recipient cells. We previously incubated platelets from splenectomized thalassemia patients with MPs isolated from splenectomized patients at 10- and 100-time higher than physiological level and significant platelet activation was found in concentration-dependent manner. ${ }^{13}$ However, the concentration of MPs (at $1 \times 10^{6}$ and $5 \times 10^{6}$ particles $/ \mathrm{ml}$ ) used in our study was about 20- and 4-fold lower than the physiological MP numbers in peripheral blood of healthy individuals $\left(2 \times 10^{7}\right.$ particles $/ \mathrm{ml}$ ) but was sufficient enough to induce endothelial cell response. Importantly, MPs from splenectomized thalassemic patients exhibited stronger effect in inducing HUVEC inflammation in dose-dependent manner. These suggest that each cell type requires different amount of MPs to exert their biological effects; nevertheless, what determinant that makes MPs from splenectomized patients to be more pro-coagulant requires further characterization. Moreover, we used MPs from the calculation of annexin- $\mathrm{V}^{+}$particles, which did not represent all of the vesicles isolated from the plasma. Other fraction of MPs, which are annexin- $\mathrm{V}^{-}$, could also act as pro-coagulant factors and might exert their effects on recipient cells' properties. We demonstrated previously, ${ }^{10-11}$ and herein, that splenectomized patients have higher levels of annexin- $\mathrm{V}^{+}$MPs compared to healthy individuals and non-splenectomized patients (Figure 1), and these MPs might be exhausted in vivo before underwent centrifugation to isolated plasma MPs for use in experiments.

Collectively, we demonstrated that MPs isolated freshly from healthy and thalassemia individuals were capable of to be internalized by endothelial cells (Figure S1) and thereby potentially induce endothelial cells to up-regulate and produce pro-inflammatory chemokines/cytokines. Particularly, 
MPs at high dose from both splenectomized thalassemia patients and healthy subjects have more potential to activate endothelial cell responses such as production of pro-inflammatory cytokines; however, the kinetics of mRNA biogenesis and protein synthesis of these mediators have to be considered. It remains to be seen how MPs are internalized into HUVECs and what biomolecules in the MPs have a significant impact on the phenotypes of the target cells.

\section{Conclusion}

Our study has indicated that plasma MPs from splenectomized $\beta$-thalassemia/HbE patients, once internalized into endothelial cells, were the most active in inducing up-regulation of several pro-inflammatory cytokines in comparison to MPs from healthy donors and non-splenectomized $\beta$-thalassemia/ $\mathrm{HbE}$ patients. Such findings support the fact that MPs are important in the dysfunction of endothelial cells and inflammation found in the context of TEEs, one of the severe complications in thalassemia patients. Exploring the biological effects of circulating MPs on endothelial cells is essential for developing improved therapeutic approaches that can practically alleviate endothelial cell dysfunction, reduce co-morbidities, and improve the life expectancy of patients with $\beta$-thalassemia.

\section{Acknowledgments}

This work was supported by the Thailand Research Fund (TRF) - Distinguished Research Professor Grant, grant number DPG5980001. The authors would like to thank the staff of the Department of Medicine, Siriraj Hospital, for help in collecting blood samples. Thanks also go to Dr. Arthur E. Brown for his valuable comments of the manuscript.

\section{References}

1. Cappellini MD, Musallam KM, Poggiali E, Taher AT. Hypercoagulability in non-transfusion-dependent thalassemia. Blood Rev. 2012;26 Suppl 1:S20-3.

2. Taher AT, Musallam KM, Karimi M, El-Beshlawy A, Belhoul K, Daar S, et al. Splenectomy and thrombosis: the case of thalassemia intermedia. J Thromb Haemost. 2010;8(10):2152-8.

3. Cappellini MD, Motta I, Musallam KM, Taher AT. Redefining thalassemia as a hypercoagulable state. Ann N Y Acad Sci. 2010;1202:231-6.

4. Atichartakarn V, Chuncharunee S, Chandanamattha P, Likittanasombat K, Aryurachai K. Correction of hypercoagulability and amelioration of pulmonary arterial hypertension by chronic blood transfusion in an asplenic hemoglobin E/beta-thalassemia patient. Blood. 2004;103(7): 2844-6.

5. Sirachainan N. Thalassemia and the hypercoagulable state. Thromb Res. 2013;132(6):637-41.

6. Aggeli C, Antoniades C, Cosma C, Chrysohoou C, Tousoulis D, Ladis V, et al. Endothelial dysfunction and inflammatory process in transfusion -dependent patients with beta-thalassemia major. Int J Cardiol. 2005; 105(1):80-4.
7. Butthep P, Rummavas S, Wisedpanichkij R, Jindadamrongwech S, Fucharoen S, Bunyaratvej A. Increased circulating activated endothelial cells, vascular endothelial growth factor, and tumor necrosis factor in thalassemia. Am J Hematol. 2002;70(2):100-6.

8. Elsayh KI, Zahran AM, El-Abaseri TB, Mohamed AO, El-Metwally TH. Hypoxia biomarkers, oxidative stress, and circulating microparticles in pediatric patients with thalassemia in Upper Egypt. Clin Appl Thromb Hemost. 2014;20(5):536-45.

9. Adly AA, El-Sherif NH, Ismail EA, El-Zaher YA, Farouk A, El-Refaey $\mathrm{AM}$, et al. Vascular dysfunction in patients with young beta-thalassemia: relation to cardiovascular complications and subclinical atherosclerosis. Clin Appl Thromb Hemost. 2015;21(8):733-4.

10. Pattanapanyasat K, Noulsri E, Fucharoen S, Lerdwana S, Lamchiagdhase P, Siritanaratkul N, et al. Flow cytometric quantitation of red blood cell vesicles in thalassemia. Cytometry B Clin Cytom. 2004;57(1):23-31.

11. Pattanapanyasat K, Gonwong S, Chaichompoo P, Noulsri E, Lerdwana S, Sukapirom K, et al. Activated platelet-derived microparticles in thalassaemia. Br J Haematol. 2007;136(3):462-71.

12. Chaichompoo P, Kumya P, Khowawisetsut L, Chiangjong W, Chaiyarit S, Pongsakul N, et al. Characterizations and proteome analysis of platelet-free plasma-derived microparticles in beta-thalassemia/hemoglobin E patients. J Proteomics. 2012;76 Spec No.:239-50.

13. Klaihmon P, Phongpao K, Kheansaard W, Noulsri E, Khuhapinant A, Fucharoen S, et al. Microparticles from splenectomized beta-thalassemia/ $\mathrm{HbE}$ patients play roles on procoagulant activities with thrombotic potential. Ann Hematol. 2017;96(2):189-98.

14. Kheansaard W, Phongpao K, Paiboonsukwong K, Pattanapanyasat K, Chaichompoo P, Svasti S. Microparticles from beta-thalassaemia/HbE patients induce endothelial cell dysfunction. Sci Rep. 2018;8(1):13033.

15. Piccin A, Murphy WG, Smith OP. Circulating microparticles: pathophysiology and clinical implications. Blood Rev. 2007;21(3):157-71.

16. Keawvichit R, Khowawisetsut L, Chaichompoo P, Polsrila K, Sukklad S, Sukapirom K, et al. Platelet activation and platelet-leukocyte interaction in beta-thalassemia/hemoglobin E patients with marked nucleated erythrocytosis. Ann Hematol. 2012;91(11):1685-94.

17. Camus SM, De Moraes JA, Bonnin P, Abbyad P, Le Jeune S, Lionnet F, et al. Circulating cell membrane microparticles transfer heme to endothelial cells and trigger vasoocclusions in sickle cell disease. Blood. 2015;125(24): 3805-14.

18. Pitanga TN, de Aragao Franca L, Rocha VC, Meirelles T, Borges VM, Goncalves MS, et al. Neutrophil-derived microparticles induce myeloperoxidase-mediated damage of vascular endothelial cells. BMC Cell Biol. 2014;15:21.

19. Frey MK, Alias S, Winter MP, Redwan B, Stubiger G, Panzenboeck A, et al. Splenectomy is modifying the vascular remodeling of thrombosis. J Am Heart Assoc. 2014;3(1):e000772.

20. Agouti I, Cointe S, Robert S, Judicone C, Loundou A, Driss F, et al. Platelet and not erythrocyte microparticles are procoagulant in transfused thalassaemia major patients. Br J Haematol. 2015;171(4):615-24.

21. Qiu Q, Xiaong W, Yang C, Gagnon C, Hardy P. Lymphocyte-derived microparticles induce bronchial epithelial cells' pro-inflammatory cytokine production and apoptosis. Mol Immunol. 2013;55(3-4):220-30.

22. Eyre J, Burton JO, Saleem MA, Mathieson PW, Topham PS, Brunskill NJ. Monocyte- and endothelial-derived microparticles induce an inflammatory phenotype in human podocytes. Nephron Exp Nephrol. 2011;119(3): e58-66.

23. Lee SK, Yang SH, Kwon I, Lee OH, Heo JH. Role of tumour necrosis factor receptor-1 and nuclear factor- $\mathrm{kB}$ in production of TNF- $\alpha$-induced pro-inflammatory microparticles in endothelial cells. Thromb Haemost. 2014;112(3):580-8. 
Supplement Table 1. Sequences of primers for real-time PCR

\begin{tabular}{|c|c|c|c|}
\hline Genes & Type & Sequence $\left(5^{\prime} \rightarrow 3^{\prime}\right)$ & Product size \\
\hline \multirow[t]{2}{*}{ CCL2 } & Forward & САCСTGCTGTTATAACTTCACCA & $164 \mathrm{bp}$ \\
\hline & Reverse & TGGAATCCTGAACCCACTTC & \\
\hline \multirow[t]{2}{*}{$C D 40$} & Forward & GGTCTCACCTCGCTATGGTT & $87 \mathrm{bp}$ \\
\hline & Reverse & CAGTGGGTGGTTCTGGATG & \\
\hline \multirow[t]{2}{*}{$I L 1 \beta$} & Forward & TACCTGTCCTGCGTGTTGAA & $76 \mathrm{bp}$ \\
\hline & Reverse & TCTTTGGGTAATTTTTGGGATCT & \\
\hline \multirow[t]{2}{*}{ IL6 } & Forward & CCTTCCAAAGATGGCTGAAA & $154 \mathrm{bp}$ \\
\hline & Reverse & AGCTCTGGCTTGTTCCTCAC & \\
\hline \multirow[t]{2}{*}{ CXCL8 } & Forward & AAGACATACTCСАААССТTTCСА & $153 \mathrm{bp}$ \\
\hline & Reverse & AACCCTCTGCACCCAGTTTT & \\
\hline \multirow[t]{2}{*}{ GAPDH } & Forward & GTCAACGGATTTGGTCGTATTG & 139 bp \\
\hline & Reverse & CATGGGTGGAATCATATTGGAA & \\
\hline
\end{tabular}
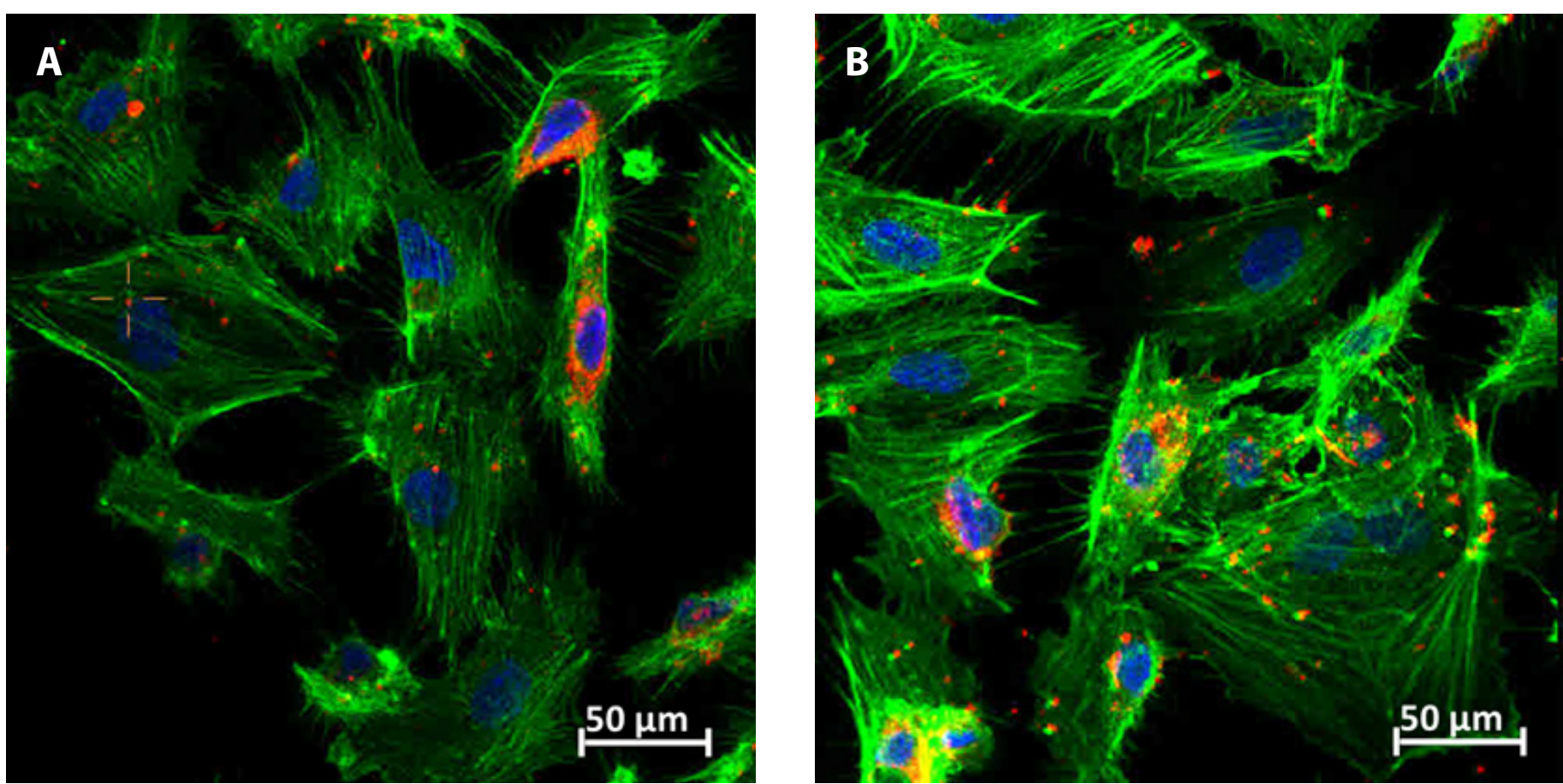

Figure S1. Representative confocal microscopic images demonstrating internalization of MPs into HUVECs at 2 h. HUVECs' cytoplasm were shown by fluorescent F-actin green fluorescence and nuclei with blue DAPI on incubation with red PKH26 fluorescent labeled MPs isolated from healthy subjects (A) and splenectomized $\beta$-thalassemia/HbE patients (B). The scale bars indicated as $50 \mu \mathrm{m}$. 